\title{
Zero-Energy-Urban-Quarter: experiences and results from a university teaching course
}

\author{
U. Dietrich \\ HafenCity University Hamburg, Germany
}

\begin{abstract}
In an architecture master course (MA), students were invited to investigate whether a feasible Zero-Energy-Urban-Quarter can be achieved and under which set of design rules.

The requirements of the task were to design living quarters for 6500 inhabitants with a density of 100 inhabitants per hectare. Each group of students had to select a plot of land located in any of the big German cities. Throughout the semester, a sequence of 4 presentations took place, where the topic was investigated and observed.

The presentations commenced with the analysis of the urban situation and a first proposal of the building arrangements, main transport axes, primary (private) central facilities, secondary (groups such as housing communities), as well as public areas.

After justifying the selection of a representative type building, it had to be further detailed and investigated as a passive house. This dealt with aspects, such as construction, materials, U-values, thermal bridges, air tightness, as well as floor plans and the installation of a mechanical ventilation system.

Detailed energy calculations were made using the well-introduced PHPP (Passivhaus-Projektierungs-Paket) tool.

After the final optimization of the prototype building, the investigation turned its focus back on aspects of urban planning. The final arrangement of the building, definition of areas for solar technology systems and secondary territories as well as a description of possible alternatives, completed the design process.

The results of this investigation concluded that it is possible to design ZeroEnergy-Urban-Quarters in Germany, with a maximum density of 100 inhabitants per hectare.
\end{abstract}


Both targets of $15 \mathrm{kWh} / \mathrm{m}^{2} \mathrm{a}$ for heating, and $45 \mathrm{kWh} / \mathrm{m}^{2} \mathrm{a}$ for primary energy, can be achieved without difficulty. For the German specification of the 2020 standard, a primary energy of $40 \mathrm{kWh} / \mathrm{m}^{2}$ a is recommended without the utilization of solar systems (i.e. collectors for hot water and PV) and $25 \mathrm{kWh} / \mathrm{m}^{2} \mathrm{a}$ when utilizing solar systems.

Keywords: Zero-Energy-Urban-Quarter, moderate climate, design rules, urban density, teaching methods

\section{Introduction}

As per the European directive of 2010/11 [1], it is claimed that in regard to the primary energy demand for heating, cooling, ventilation, hot water and artificial light, only (Nearly-) Zero-Energy-Buildings may be built within the 2020 standard.

Thus, buildings have to be energetically optimized, utilizing a choice of passive means, such as thermal insulation, shading system, daylight, natural ventilation and thermal storage mass. Any additional energy demand, needs to be covered by renewable energies which has (following the directive) to be gained "nearby", i.e. in a purist definition - from the surfaces of the building (PV and thermal collectors) or its direct neighbourhood (e.g. the ground with heat exchangers for heating and cooling energy).

Due to the competitiveness between the area of use (producing energy demand) and the size of the building envelope/the estate for the harvest of renewable energies, the number of storeys that can be built are limited. This in turn limits the area available for PV-modules and collectors, as well as for the minimum building distances (because of shading between buildings; geothermal systems).

Both aspects have strong consequences for the resulting urban density, and thus urban planning.

This subject should be investigated in a MA course in architecture; the workload for students was $5 \mathrm{CP}$ which is equivalent to 150 hours working in groups of up to three participants.

\section{Zero-Energy-Urban-Quarters: state of the art}

In Germany, the meaning of the terms "nearly" and "nearby", have not been defined, which is even included in the new standard of 2014. The definitions are to be announced for the upcoming release in 2016, and it has been stated that this is placed on hold, for the intent to transfer it into practice starting with 2018 for public buildings and 2020 for all new buildings.

Regarding this very unsatisfactory situation in Germany, the existing standard from the neighbouring country of Belgium [2], which has a very similar climate, was selected as base for verification of the target. This standard has a clear definition: $15 \mathrm{kWh} / \mathrm{m}^{2} \mathrm{a}$ for heating (which means a passive house) and $45 \mathrm{kWh} / \mathrm{m}^{2} \mathrm{a}$ for primary energy for residential buildings. These $45 \mathrm{kWh} / \mathrm{m}^{2} \mathrm{a}$ contain the primary energy for heating, cooling, ventilation and domestic hot water but not the demand for artificial light as for non-residential buildings. 
To date, two concepts for low energy buildings are known: the passive house as "energy safe" and the solar house using regenerative building services. Passive houses are often designed as a south-oriented funnel and thus a north-oriented roof. Solar houses are asking, vice versa, for a south-oriented roof which could be covered with modules and collectors.

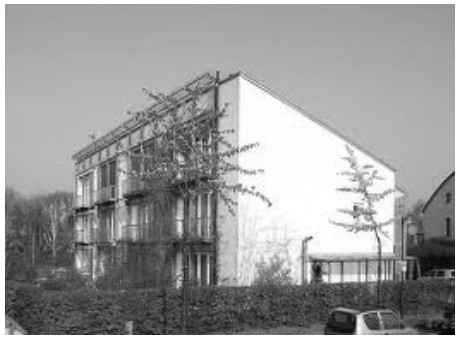

(a)

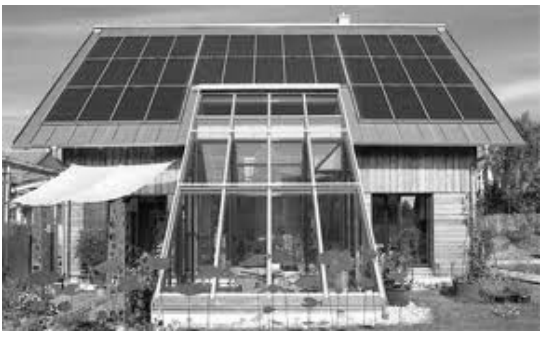

(b)

Figure 1: Comparison of a typical design for a passive house ((a) passive house Darmstadt) and a solar house ((b) Solarhaus 50+ at the Intersolar exhibition).

It can be seen that a synthesis of both concepts is necessary to reach the ZeroEnergy target.

Solutions for single Zero-Energy-Buildings do exist, but currently there are no well-developed concepts for urban quarters nor relevant design rules respectively.

In reality, the urban situation is taken as it is and one tries to design a single Zero-Energy-Building in it. But on reflecting the background, it is essential to start with aspects of urban planning which are already on a political level with presettings such as a central given maximum density to fulfil the topic.

\section{Task and sequence of the university course}

\subsection{Task}

The task assumed the following situation: In a growing town in Germany, a new residential quarter for 6500 inhabitants should be developed. The student groups were allowed to choose a town and the plot of land, which resulted in different, but comparable results, due to different climatic conditions within Germany.

It was pre-estimated that an urban density of not more than 100 inhabitants/ha seems to allow a Zero-Energy-Urban-Quarter. For comparison, existing urban quarters in Germany with a very high density have between 150 and 200 inhabitants/ha, thus 100 is a medium density, which is the most common range of the existing quarters.

During the course, it was investigated whether this assumption was a good presetting or if Zero-Energy-Urban-Quarters can be reached only with lower densities, and furthermore, if even higher densities would be possible. 
It was concluded with the students, that pure residential quarters are not an optimal solution for urban planning as this causes traffic between living and working. A mixture in the type of use between residences and offices would be a better option. This fact though was neglected to ease the task.

\subsection{Sequence of steps}

The subject was investigated in a sequence of 4 short presentations during the semester. It began with the specialties of the chosen plot of land and proposals for the placement of buildings on it, continuing with the choice of one representative building for which the energy demand was simulated to decide to what extent Zero-Energy is reached by optimizing this building, and ultimately going back to aspects of urban planning and deriving design rules for Zero-Energy-Buildings, as well as for their arrangement in an urban situation.

The student groups were required to express the discussions they had among themselves and apply their ideas. This was a central focus of the course and played an important role in improving their results, finding the best solutions and allowing them to obtain and discuss the final design rules for buildings as well as urban planning.

\subsubsection{Content of the first short presentation}

With regard to the chosen town and plot of land, the connection to the existing grid of private and public traffic should be explained first, and the resulting main axes in the new quarter derived.

Each student in a group had to select a layout for the prototype buildings, analyze as well as present them in regard to access of daylight and solar radiation to the façades, and to the size and orientation of possible areas for solar systems on the roofs and façades.

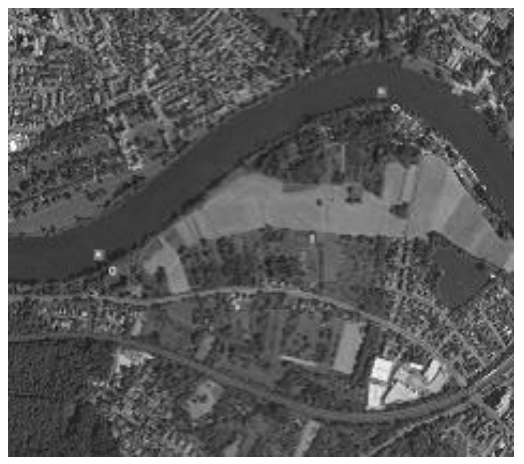

(a)

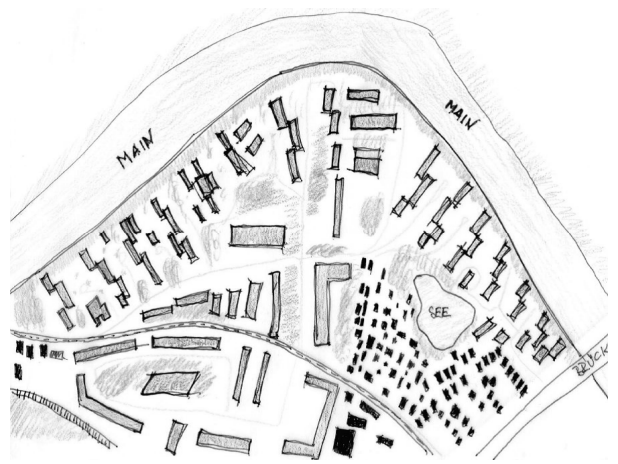

(b)

Figure 2: Example for a chosen town and plot of land (a) and a first proposal for one possible layout of the buildings (b) according to the given urban density (Faber et al. [3]). 
Regarding the different proposals of the arrangement of buildings, their strengths and weaknesses had to be investigated and summed up in an explanatory statement, and a final decision for the choice had to be obtained.

\subsubsection{Intermediate warming up for aspects of urban planning}

To familiarise architects with aspects of urban planning, simple quick reports were inserted dealing with an analysis of their own personal lives.

Firstly, students had to report about their daily routines in their own quarter and analyze the number of routes and their distances for walking and cycling. As a result, they noted that they all undertake roughly 5 routes a day. Their typical distance being about 5-15 min (this distance should be within the radius to the next station for public transport, bakery, shops, etc.) which is the equivalent of 500-1000 $\mathrm{m}$ for walking and a few km for cycling.

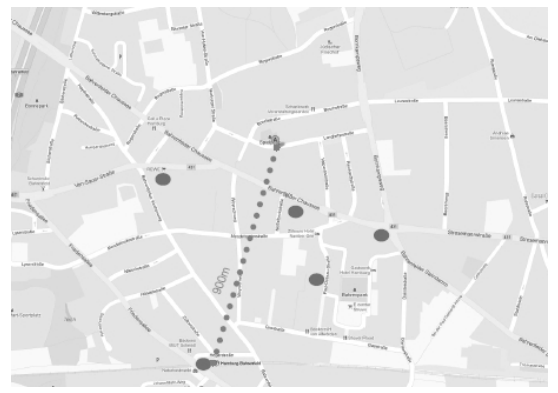

(a)

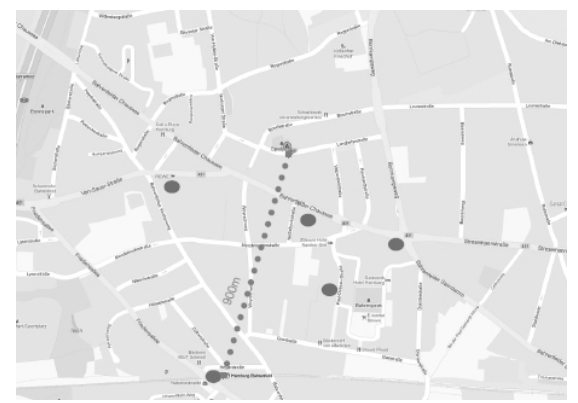

(b)

Figure 3: Example of an analysis of the daily routes by foot (a) points mark the targets; the dotted line a typical distance of $900 \mathrm{~m}$ and by bicycle (b) the typical length is $3200 \mathrm{~m}$ ) (Schmidt [4]).

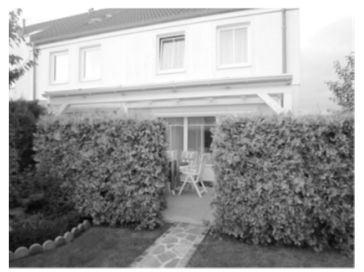

(a)

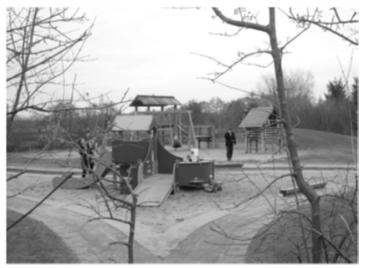

(b)

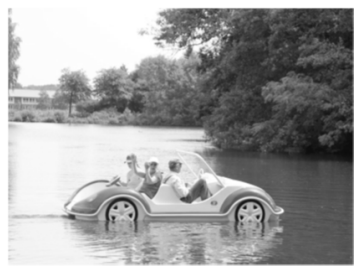

(c)

Figure 4: Example for an analysis of primary (a), secondary (b) and public territories (c) in their own surroundings (Günther [5]).

Then students had to analyse the primary (private), secondary (used by a definite group like residents of a building) and public territories in their surroundings to understand how all three types are necessary for everyday life and should be part of their urban design. 


\subsubsection{Content of the second short presentation}

The final layout proposal of the urban quarter had to take into consideration aspects of the public infrastructure like bus and train stations, streets, car and cycle parking, kindergarden, supermarket as well as primary, secondary and public territories. Areas which allowed for possible use of solar technology systems had to be defined on the roofs and façades of the buildings as well as in the free space between them.

Finally, one representative building had to be selected as a prototype building for further detailed investigation as a passive house.

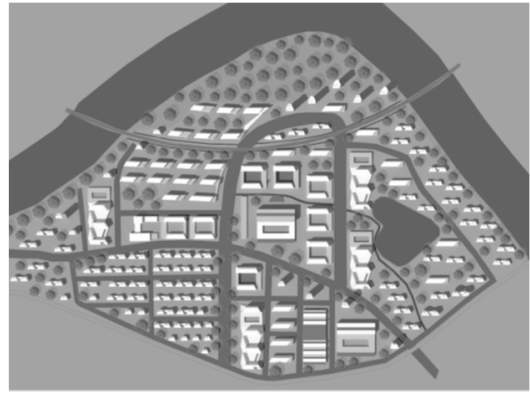

(a)

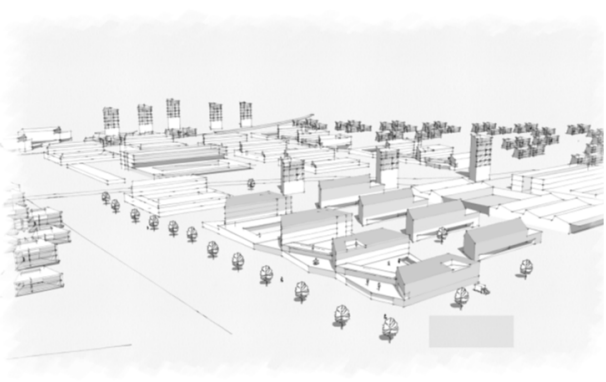

(b)

Figure 5: Example for the final alternative for the urban situation (a) with arrangement of buildings and analysis of possible areas for solar technology systems (b) (Faber et al. [6]).

\subsubsection{Content of the third short presentation}

The main focus of the entire course dealt with the optimization of the selected building prototype as a passive house. For this purpose, all the necessary detailing was realized:

- Definition of the thermal envelope of the building;

- Cross-sections of all constructions (walls, roofs, floors) forming these thermal envelopes with definition of layers for thermal insulation as well as for air tightness;

- Definition of materials and calculation of U-values of all constructions;

- Floor plans and sections with shafts located for mechanical ventilation;

- Details of intersections between different constructions (wall on floor, wall on roof, window in wall etc.) with concrete solutions and descriptions free thermal bridge achievement and air tight construction.

At last, all this information was used for a simulation of the heating energy demand with the PHPP program (PHPP [9]). Due to the fact that passive solar heat gains have a decisive influence on the heating demand, the shadowing of the neighbouring buildings was also investigated in detail. 


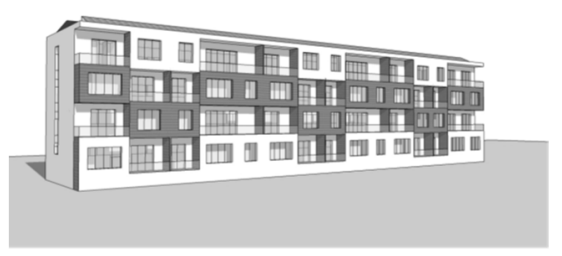

(a)

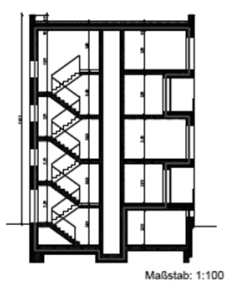

(b)

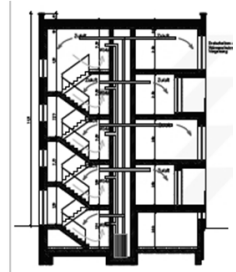

Figure 6: Example for the choice of a building prototype (a) and sections with the definition of the thermal envelope and the shafts for mechanical ventilation (b) (Günther [7]).

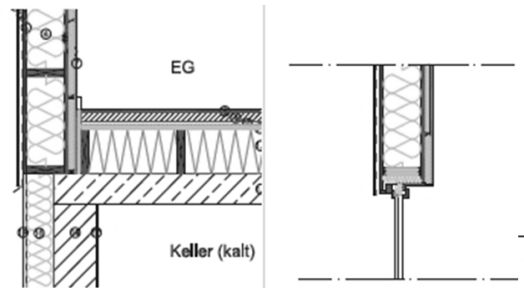

(a)

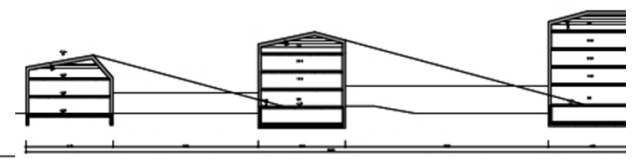

(b)

Figure 7: Example for intersections with the description of thermal bridge free and air tight construction (a) and an analysis of the shadowing between buildings (b) (Faber et al. [8]).

Since the main task for the students of architecture was to optimize the building and not its building services, the building services according to the reference building of the German standard (EnEV 2009 [10]) were assumed. However, some of these settings make no sense for a passive house. In this case, the standard assumptions from EnEV were replaced by the minimal preconditions for a passive house (e.g. the percentage of heat recovery, distribution of heat by air instead of water).

In this third short presentation, the possible reduction of primary energy demand with solar technology systems was still neglected. The target was to estimate where we stood with the initial trial of the prototype building as a passive one.

This was simulated with PHPP, indicating whether the prototype building is below or above the limit of $15 \mathrm{kWh}$ for heating and $45 \mathrm{kWh}$ for primary energy. If these limits were not achieved, the student groups had to propose further optimization solutions as the conclusion of this presentation.

\subsubsection{Content of the final short presentation}

Students needed to find out measures influencing the optimization process. Building shape and thermal envelope influence the thermal energy loss, windows oriented towards the sun can increase passive solar heat gains. Also, passive solar 
heat depends strongly on orientation and location of buildings on site. Thus, aspects of urban design can also contribute to the optimization process.

Also, when and if results fall below $15 \mathrm{kWh} / \mathrm{m}^{2}$ a for heating and $45 \mathrm{kWh} / \mathrm{m}^{2} \mathrm{a}$ for primary energy, changes in design at an architectural and urban level and orientation of the building are possible until these energy limits are reached:

- Deviation from strong south orientation;

- Less compact building shape with terraces, loggias etc.;

- Bigger windows also on east/west/north façades (allowing to install main areas of use there);

- If south oriented buildings undercut the thresholds remarkably, thresholds can be regarded as a mean value over all the buildings, allowing (a limited) number of east-west oriented buildings which lay above the thresholds;

- Reduction of building distances to improve urban situation.

The optimized version of the prototype building as well as the arrangement of the buildings in their urban situation was presented. All groups had already reached the primary energy target of $45 \mathrm{kWh} / \mathrm{m}^{2}$ a without the use of solar technology systems.

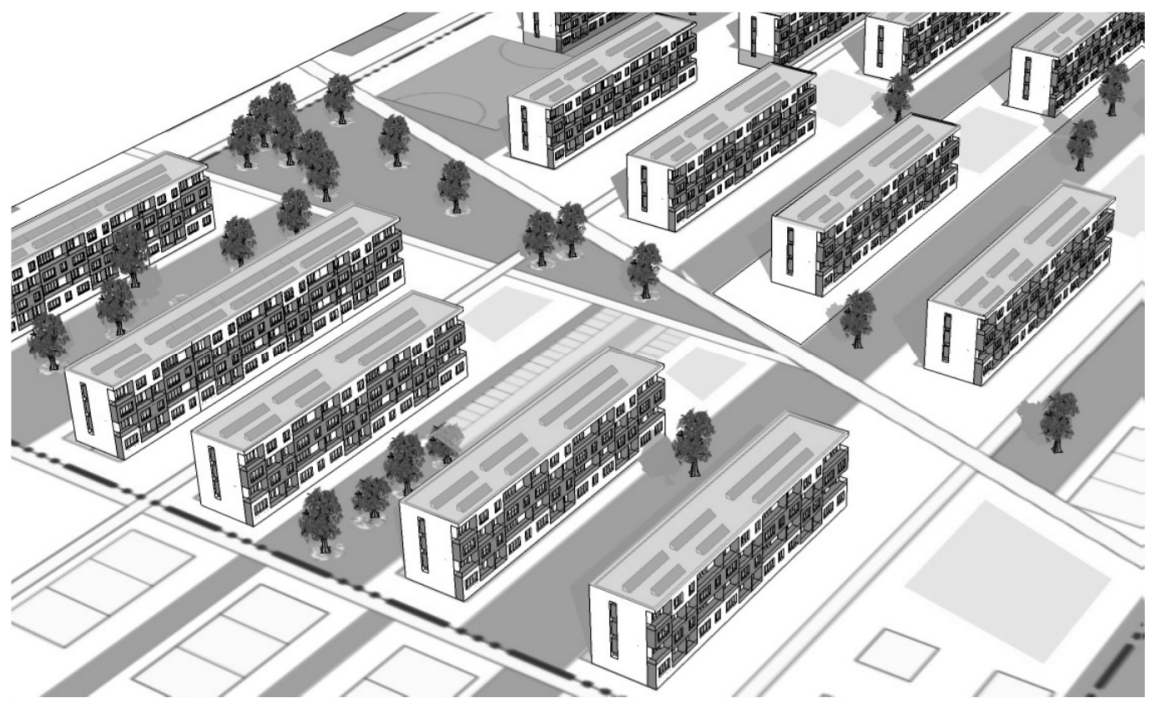

Figure 8: Example for the optimization of the building prototype as well as their positioning in the urban situation. Unshaded areas for solar technology systems are marked. Note the location of trees respecting the free access of solar radiation to the south façades (Günther [11]).

In a further step, it was investigated as to which value the primary energy can be lowered with solar technology systems on site. 
Per definition, this primary energy doesn't contain the tenant's power demand, which is about $25 \mathrm{kWh} / \mathrm{m}^{2} \mathrm{a}$ in Germany. Therefore, a so-called Zero-EnergyBuilding is still not a real one, due to the tenant's power demand which remains undefined. A further investigation was done to see whether this demand could be covered with PV-modules on site to reach a real Zero-Energy-Building. These results will be discussed in chapter 4 .

The final presentation had to conclude with a statement of the student groups in regard to the process that they experienced: Was there a feeling of limitation in freedom of design? Or did the ancillary conditions lead to different design concepts and to different and satisfying solutions?

\section{Results}

\subsection{Energy}

For different locations within Germany, the primary energy target of $45 \mathrm{kWh} / \mathrm{m}^{2} \mathrm{a}$ can be reached without difficulty, even without the use of solar technology systems. For the German version EnEV 2020, a value of $40 \mathrm{kWh} / \mathrm{m}^{2} \mathrm{a}$ appears to be realistic. Here it should be mentioned that naturally, we used the German calculation method, but the Belgian value of $45 \mathrm{kWh} / \mathrm{m}^{2} \mathrm{a}$ for primary energy, should be in accordance with their own values, which could be stronger, which we are currently unaware of.

With small solar technology systems (per person of about $0.75 \mathrm{~m}^{2} \mathrm{PV}$ and $0.5 \mathrm{~m}^{2}$ collector resulting in $1.25 \mathrm{~m}^{2}$ ), the auxiliary power demand for heating and ventilation, including approximately half of the hot water demand, can be covered. An area for solar technology systems in this range can be arranged without difficulty on the roofs of even multi-storey buildings. With these solar technology systems, a primary energy of $25 \mathrm{kWh} / \mathrm{m}^{2} \mathrm{a}$ can be reached. This value can be recommended as the boundary for the German standard for a Nearly-Zero-EnergyResidential-Building.

To further cover the power demand of the tenants of $25 \mathrm{kWh} / \mathrm{m}^{2}$ a (e.g. inclusive artificial light), the area of a (even pitched) roof, tends to be too small. Supplementary area for PV (south façades, roofs of car parks, terraces, pergolas etc.) must be defined, or compensating measures will be necessary - the real ZeroEnergy-Building is difficult to reach in an urban situation.

\subsection{Urban density}

The density of 100 inhabitants/ha is a good assumption to obtain a Zero-EnergyUrban-Quarter. But with higher densities, this target would be increasingly difficult, or impossible to reach.

100 inhabitants/ha means - with $35 \mathrm{~m}^{2} /$ person - a living area of $3500 \mathrm{~m}^{2}$, with a factor of 2 (for stairs, walls etc.) a gross area of $7000 \mathrm{~m}^{2}$, giving a plot ratio of 0.7 which is a value in the middle range. Vice versa, quarters with very high densities cannot be Zero-Energy; compensating measures would be necessary. 
For future newly planned urban quarters, this density is recommended as a maximum value.

\subsection{Experience of student groups}

A positive experience of the students of architecture was that they did not feel restricted in their freedom of design; but much more encouraged to find different design solutions for different ancillary conditions.

\section{Derivation of general design rules for Zero-Energy-Urban-Quarters}

The climate at the location has a considerable influence. If higher temperatures and more solar radiation are available in the heating period, the passive house target can be reached more easily, and therefore more degrees of freedom in design are possible. The difference in heating energy demand for the same building between north (Hamburg) and south (Freiburg) of Germany is about $6 \mathrm{kWh} / \mathrm{m}^{2} \mathrm{a}$ or $40 \%$. Thus, design in the south!

\subsection{Rules for urban planning}

The basic principle is to design big and compact buildings with main orientation of north-south (length in minimum $40 \mathrm{~m}$ ).

To reach a good urban density, buildings with 4 or 5 storeys are optimal; the building depth should follow a good daylight situation with about $15 \mathrm{~m}$, leading to a ratio envelope/volume below 0.35 .

The arrangement of buildings must strictly follow the principle that buildings may not shade each other. This can be reached with identical building heights or with a graduation in building height from south to north. A good solution for urban planning seems to be an arrangement of buildings in clusters with increasing building height from south to north (reaching a high urban density) and behind the last (highest) building a big space for a public territory and then the next cluster of buildings. But also with a renaissance of urban planning rules from the 19th century - central, given identical maximum number of storeys and building heights like in Paris - a good solution is possible.

In order to allow for good access of daylight and sun onto the façades, a minimum distance between the buildings which is calculated as twice the building height, is necessary. With building heights of 12 to $15 \mathrm{~m}$ (4 or 5 storeys), distances between 24 and $30 \mathrm{~m}$ occur. Such distances are good for a street, parking for cars and cycles, secondary territories, etc.

South façades should be kept unshaded; big trees should not be planted too close in front of the south façades at an angle of between SE and SW.

The building is nearly robust against a change in orientation of $+/-30^{\circ}$ out of south - this opens degrees of freedom for urban planning and curved streets. 


\subsection{Rules for buildings}

Besides standard rules for passive houses like U-values, air tightness, etc., the building has to be designed as a synthesis between a passive and a solar house.

The portion of windows in the façades is recommended as south $60-75 \%$, east/west $20-40 \%$ and north $20-40 \%$. Furthermore, if it is possible to reach the $15 \mathrm{kWh} / \mathrm{m}^{2}$ a passive house target with a higher portion of windows in the north façade $(>40 \%)$, the building tends to be relatively robust against changes in orientation - each loss from turning out of south is nearly compensated by turning the north façade to east or west respectively.

Floor plans should be arranged so that the main living rooms are situated on the south and that staircases, kitchens, and bathroom are situated in the north.

A south oriented pitched roof allows the occupancy of the whole area for solar systems (a flat roof with elevated collectors can only use about $40 \%$ of the roof area because of their distance). With a slope of $15-20^{\circ}$ a good compromise is reached between the energetic optimum $\left(30-35^{\circ}\right)$ and a low roof ridge (to reduce shadowing the next building). About half of the roof volume can be used as a (north oriented) area of use for the lower apartment, thus forming a maisonette.

A construction principle with heavy, load bearing walls inside of the buildings and light, insulated walls (wood construction) as façades has certain advantages: thinner external walls, double use of thermal storage mass in internal walls. On a façade of wooden construction, it is easily possible to fix solar modules (PV) but on a massive wall with external $30 \mathrm{~cm}$ thermal insulation this seems to be difficult.

A harsh climate would require a compact building without any exceptions. If the climate is a bit more moderate, some exceptions to the rule are possible, such as balconies on the south façade or even the breaking of the strong south façade into a field of loggias and terraces allowing the design of primary territories.

\section{References}

[1] Directive 2010/31/EU of the European Parliament and of the Council of 19 May 2010 on the energy performance of buildings, Brussels, 2010

[2] Arrêté du Gouvernement de la Région de Bruxelles-Capitale portant modification de divers arrêtés d'exécution de l'ordonnance du 7 juin 2007 relative à la performance énergétique, Moniteur Belge, 14 September 2009

[3] Faber, F., Schmidt, K. \& Mylopoulou, A., Zero-Energy-Urban-Quarter, first short presentation, MA course, Hafencity University, 2012

[4] Schmidt, K., Analysis of my daily ways, MA course, Hafencity University, 2012

[5] Günther, H., Analysis of primary, secondary and public territories in my surroundings, MA course, Hafencity University, 2012

[6] Faber, F., Schmidt, K. \& Mylopoulou, A., Zero-Energy-Urban-Quarter, second short presentation, MA course, Hafencity University, 2012

[7] Günther, H., Zero-Energy-Urban-Quarter, third short presentation, MA course, Hafencity University, 2012 
[8] Faber, F., Schmidt, K. \& Mylopoulou, A, Zero-Energy-Urban-Quarter, third short presentation, MA course, Hafencity University, 2012

[9] PHPP, Passivhaus-Projektierungspaket 7, http://www.passiv.de/de/04 phpp/04 phpp.htm, 2013

[10] EnEV 2009, Energieeinsparverordnung, Bundesministerium für Verkehr, Bau und Stadtentwicklung, 2009

[11] Günther, H., Zero-Energy-Urban-Quarter, final presentation, MA course, Hafencity University, 2012 